The International Journal Of Engineering And Science (IJES)

|| Volume || 6 || Issue || 1 || Pages || PP 05-11 || 2017 ||

ISSN (e): $2319-1813$ ISSN (p): $2319-1805$

缊证

\title{
Assessment of Indoor and Traffic Air Pollution in Ambo, Oromia Region, Ethiopia: A Review
}

\author{
*Thanappan Subash ${ }^{1}$, Dhanasekaran ${ }^{2}$, Sathya Prabha ${ }^{3}$ \\ ${ }^{I}$ Department of Civil Engineering, Ambo University, Ambo, Ethiopia. \\ ${ }^{2}$ Department of Civil Engineering, Ambo University, Ambo, Ethiopia. \\ ${ }^{3}$ Department of Civil Engineering, Ambo University, Ambo, Ethiopia.
}

\begin{abstract}
Air plays a vital role to support the life system of all kind of living things in the biosphere. Air is defined as the elastic, invisible and tasteless mixture of gases that surrounds the earth. Quality of air is being changed day to day, due to the natural and anthropogenic activities. The simultaneous growth of urbanization, industrialization and transportation leads to air pollution, which causes severe impact on the environment. Emissions from different sources like Point, Area and Line are considered as serious air pollutants responsible for air pollution. The atmosphere, as a matter of fact, contains hundreds of air pollutants from natural and anthropogenic sources. All such pollutants are primary pollutants. The important primary pollutants are: sulphur oxides, carbon monoxide, nitrogen oxides, hydrocarbons etc. Such air pollutants are to be identified and characterized along with their sources, in order to describe the present air environment strategies in Ambo town, Ethiopia. Annual emission concentration of these pollutants is to be assessed with the consideration of total annual fuel usage in various sources and appropriate emission factors.
\end{abstract}

Keywords: Biomass fuel, Carbon monoxide, Hydro carbon, Nitrogen oxides, Sulphur dioxide, Pollutants

Date of Submission: 06 January 2017

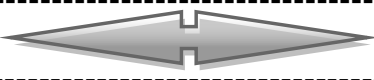

Date of Accepted: 20 January 2017

\section{INTRODUCTION}

More than 50\% of the global population heavily relies on biomass fuel as a source of household [1]. Exposure to indoor air pollution (IAP) from the combustion of coal, crop residues, animal dung and biomass fuel is highly affecting the lives of 3 billion people all over the world [2-7]. Moreover, diseases like suffocations on respiratory system, infections in the respiratory tracks and chronic obstructive lung diseases are very common link with indoor and traffic air pollution [8-10]. Mainly, Indoor air pollution is strongly associated with ARI was also demonstrated in African countries [11-16]. Traffic air pollution is more specific to ambient air pollution. The major source of air pollution in urban areas originates from vehicles [Figure 2]. Due to the growth of transportation, an increased level of traffic air pollution was observed in most urban areas in developing countries like Ethiopia [15, 17-22]. The current ambient air pollution level in urban areas of developed countries is 10-20 times less than that of developing countries [23]. Ambo town in Ethiopia is not an exception to the reality of air pollution. Over $90 \%$ of residents in ambo town use biomass fuel, coal and animal dung for burning, especially for cooking purpose [24, 25]. Nevertheless, the present level of both indoor air pollution and ambient air pollution has not been studied in Ambo town. The current review would help one to involve an in-depth investigation into the status of indoor air pollution and traffic air pollution in the study area. The population of human beings increases day by day due to the development of urbanization, mainly due to the various government educational sectors, namely, Ambo University main campus, Awaro campus for Institute of Technology, Ambo University Guder campus for plant science and other various activities in Ambo town. Living in crowded and poorly ventilated housing [Figure 3], and limited access to separate cooking and living areas in rural and urban homes are visible features of living conditions in Ambo [26]. The use of biomass fuel for cooking by the majority of families in poorly designed houses [Figure 3] is another major cause of exposure to IAP. The harmful effects caused to human being by the polluted air depend upon the type and concentration of the pollutants present in the air. The polluted air, not only is harmful to man, but is also harmful to all types of life, including plants, animals and birds. It is also harmful to non-living materials, like, marbles, metals, and other stones, woods, paints, papers, etc. which get spoiled by the contact with polluted air, either due to the more physical corrosive action of polluted air, or/and due to the chemical attack of the pollutants on such materials. Thus air pollution is an environmental evil. 


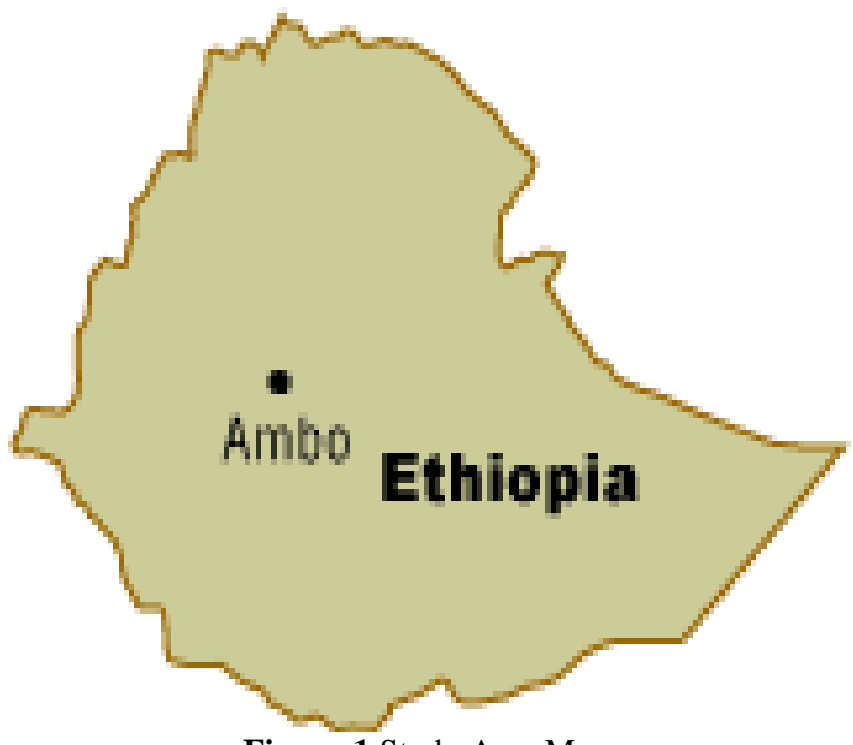

Figure-1 Study Area Map

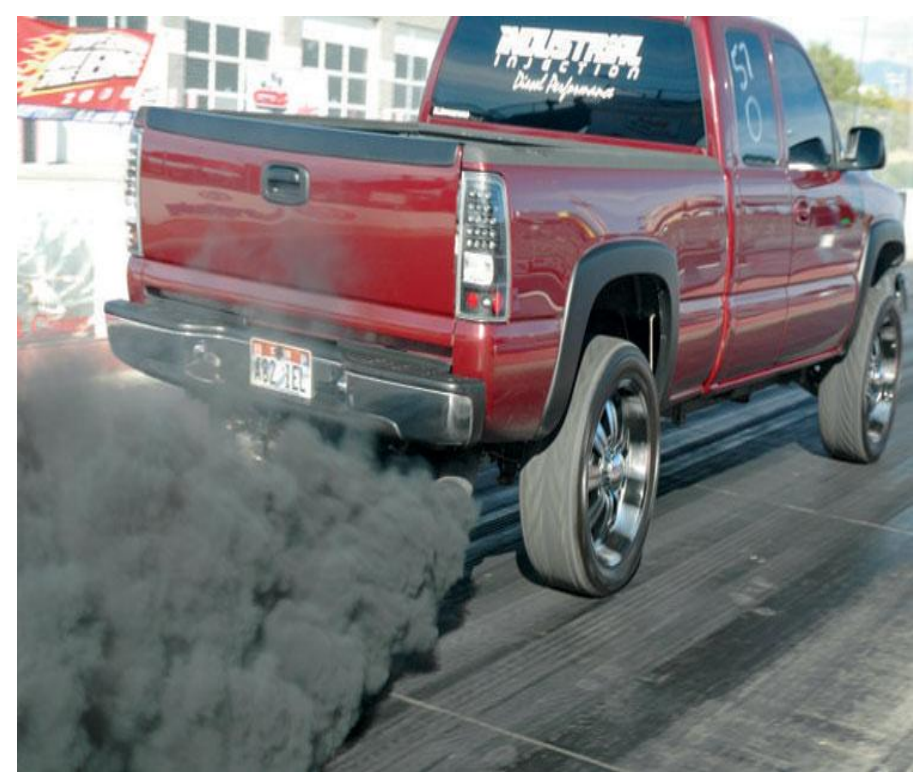

Figure 2 Emissions from Vehicular Exhaust in Ambo Town

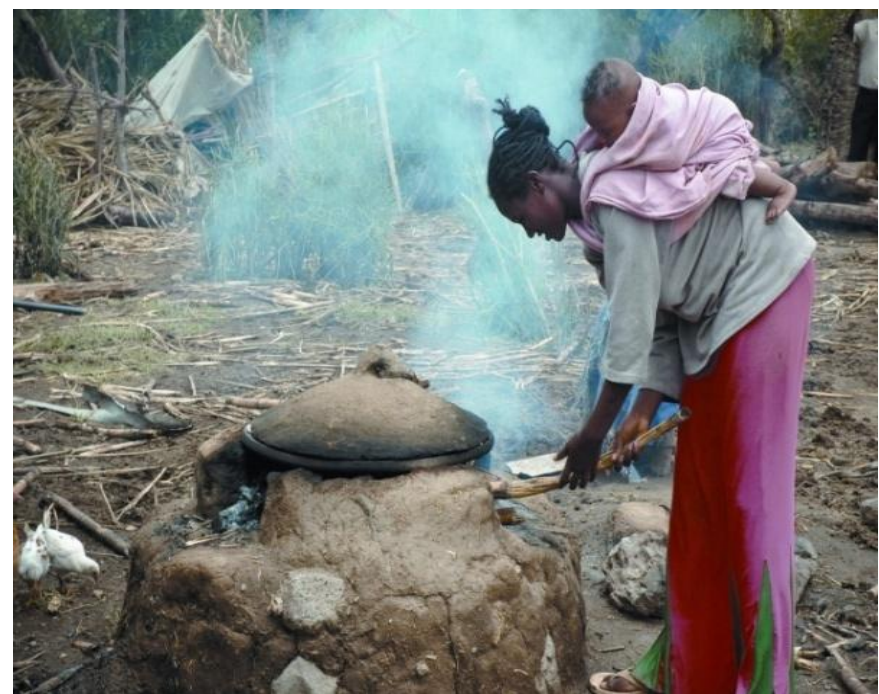

Figure-4 Emission Exhaust from Wood Burning 


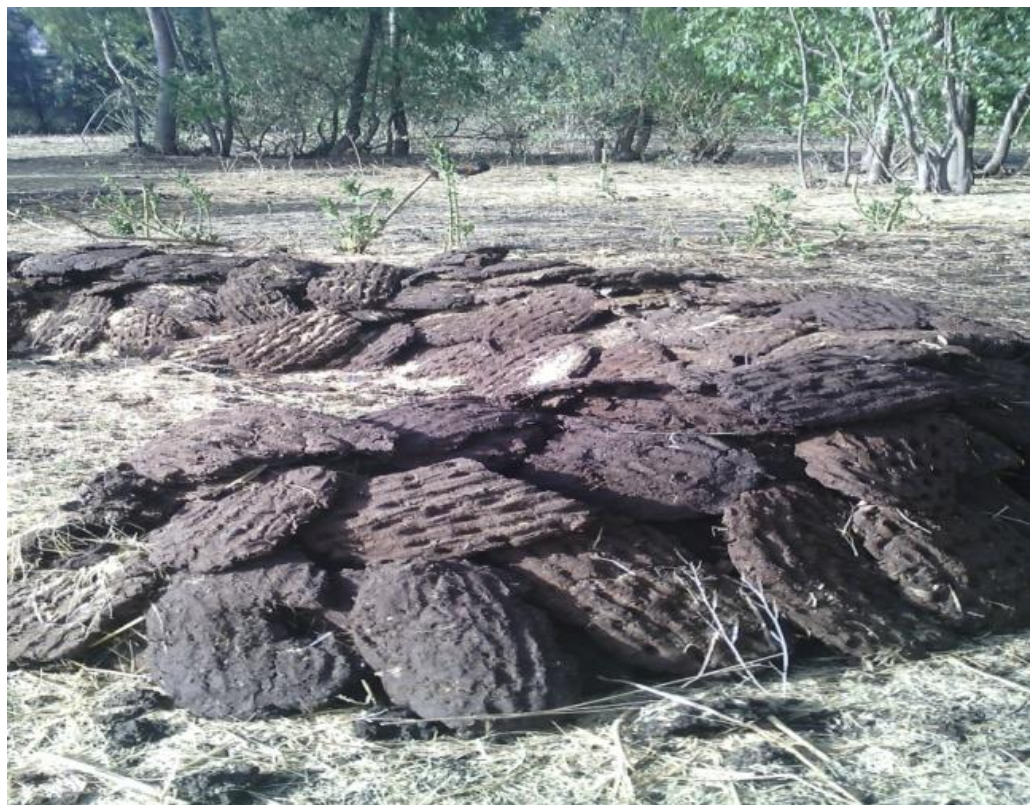

Figure-5 Cow Dungs used for Fuel in Ambo Town

\subsection{General objective of the study}

Primary ambient air quality standards which are required to safeguard the health of population, and secondary ambient air quality standards required to protect the public welfare such as buildings, soil, water, visibility, and vegetation. World Health Organization provides international air quality guidelines that can be adopted or modified by each member country based on socio-economic conditions.

- To identify the emission sources through Point, Area and Line.

- To study the character of fuel usage and its volume on an annual basis for different sources.

- To select appropriate emission factors suitable for different fuel usage in the study area.

- To estimate ward wise annual total concentration of each pollutant emitting from the sources.

- To prepare various thematic maps to show the present trend of urban air environment using GIS software and to create a strong data base for emission inventory in Ambo town which helps for further updating.

\subsection{Introduction of prior relevant work}

The first effort was made in the capital city of Ethiopia, Addis Ababa, by Etyemezian et al in the year 2004 in which 12 air sampling residential sites with $\mathrm{CO}$ and other proxy measurements were taken. The second similar work have been conducted in a rural Butajira and in Addis Ababa, the capital city of Ethiopia, by Abera Kumie [26], in which the profile of CO concentrations by time was not similar with the earlier study conducted by Etyemezian [27].

\section{DESCRIPTION OF STUDY AREA}

The study area 'Ambo' is located in the West Shewa Zone of the Oromia Region, west of the capital city, Addis Ababa [Figure 1]. The town has latitude of $8^{\circ} 59^{\prime} \mathrm{N}$ and longitude of $37^{\circ} 51^{\prime} \mathrm{E}$ and an elevation of 2101 meters from MSL. A Crater Lake, "Mount Wenchi" to the south of Ambo, the Guder and the Huluka Falls are very famous elegant places in the study area. A research station of the Ethiopian Institute of Agricultural Research was initiated in the year1977 in the study area, and this station hosts research in protecting major crops in Ethiopia. The total population of 94,342 was reported in the year 2012 .

\section{METHODS AND MATERIAL FOR THE PROPOSED STUDY}

Rapid survey method of emission inventory yield annual, seasonal, daily or hourly average emissions [27]. The detailed emission inventory should contain sufficient data to specify the quantities of emissions and the compliance status of atleast those pollutants recommended by EPA. Various activities to be carried out for emission inventory is shown in the flow diagram [Figure 6]. For the collection of data, various sources of emission to be identified [Figure 7]. Data for point and area sources to be collected through questionnaire, Telephonic interview with the owners of industries, experts, house owners etc [Figure 8]. For the identification of number of vehicles exhaust emissions, traffic study to be done with the help of manpower and local traffic police men. 


\subsection{Stationary Source Identification}

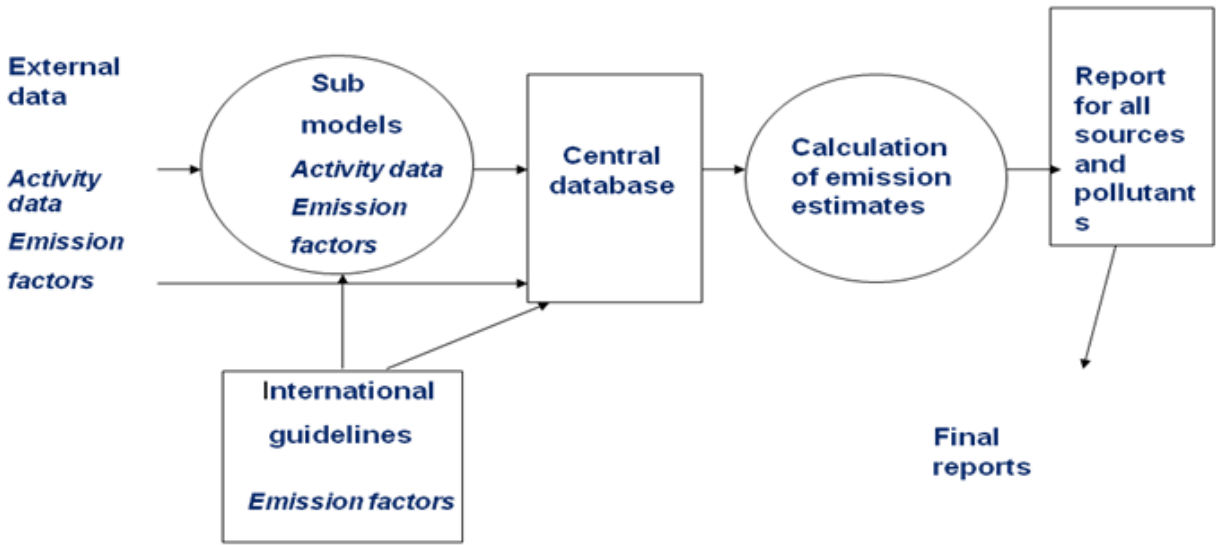

Figure-6 Activities to be carried out for Emission Inventory
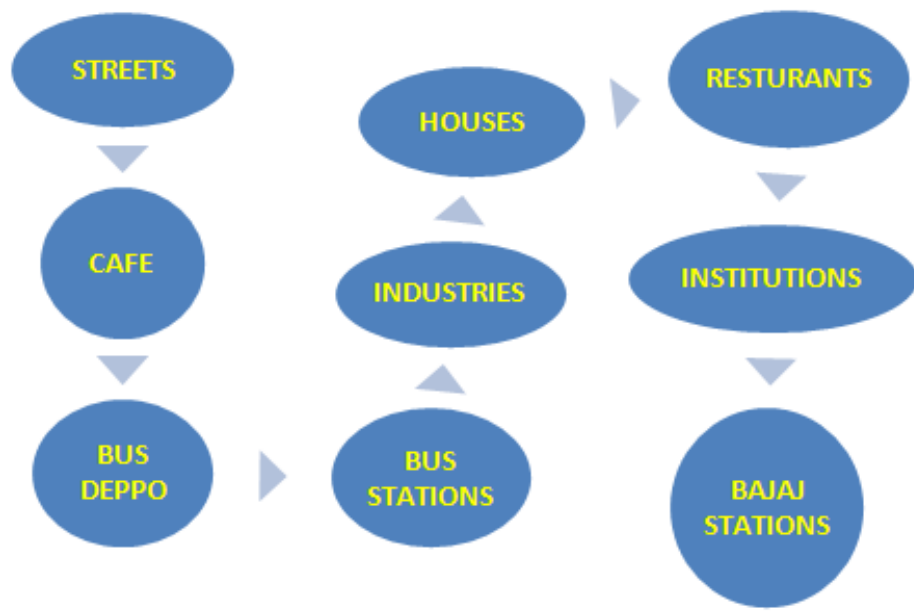

Figure-7 Sources of data Collection for Emission Inventory

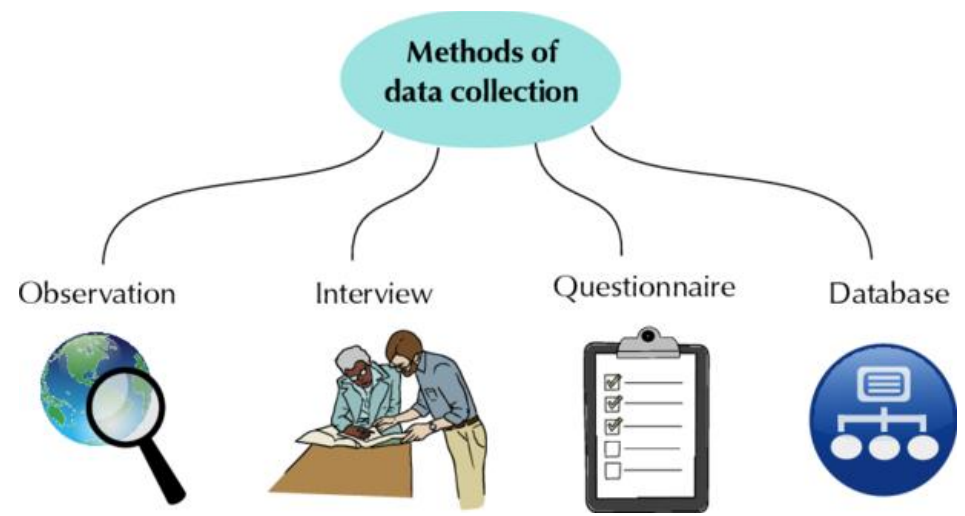

Figure-8Methods of data Collection

\subsubsection{Point sources:}

To adequately define each individual point sources in the particular study area, the following information to be collected.

General information

- Distribution of point sources

- Address and phone number of owner of the industries

- Year of record to indicate the date of data collection or update

- To identify the basic process or industrial activity

Fuel consumption data: Consumption rate - fuel consumed per day could be tied with in with the sources classification code to facilitate recalculation of emissions using factors. 


\subsubsection{Area sources}

General information to be collected include:

- Collection of many small unidentifiable stationary points of air pollution emissions.

- Emissions from sources too small to be surveyed individually and reported collectively as area sources.

- Year of record to indicate the date of data collection or update

- To identify the basic process or industrial activity

Consumption rate - fuel consumed per day. This amount could be tied with in with the sources classification code to facilitate recalculation of emissions using factors.

The source categories include:

- Residential heating - residential dwelling from single family residences to multistory apartment complexes [Figure 4,5].

- Commercial heating - hotels, café, noon meal centers, government buildings, bus station and other public facilities.

\subsubsection{Line sources}

Source inventory data in the form of daily or hourly average vehicle counts - count of light, medium, and heavy vehicles in the main roads of the study area will be collected [Figure 9] for the route for the use in application of emission factors.

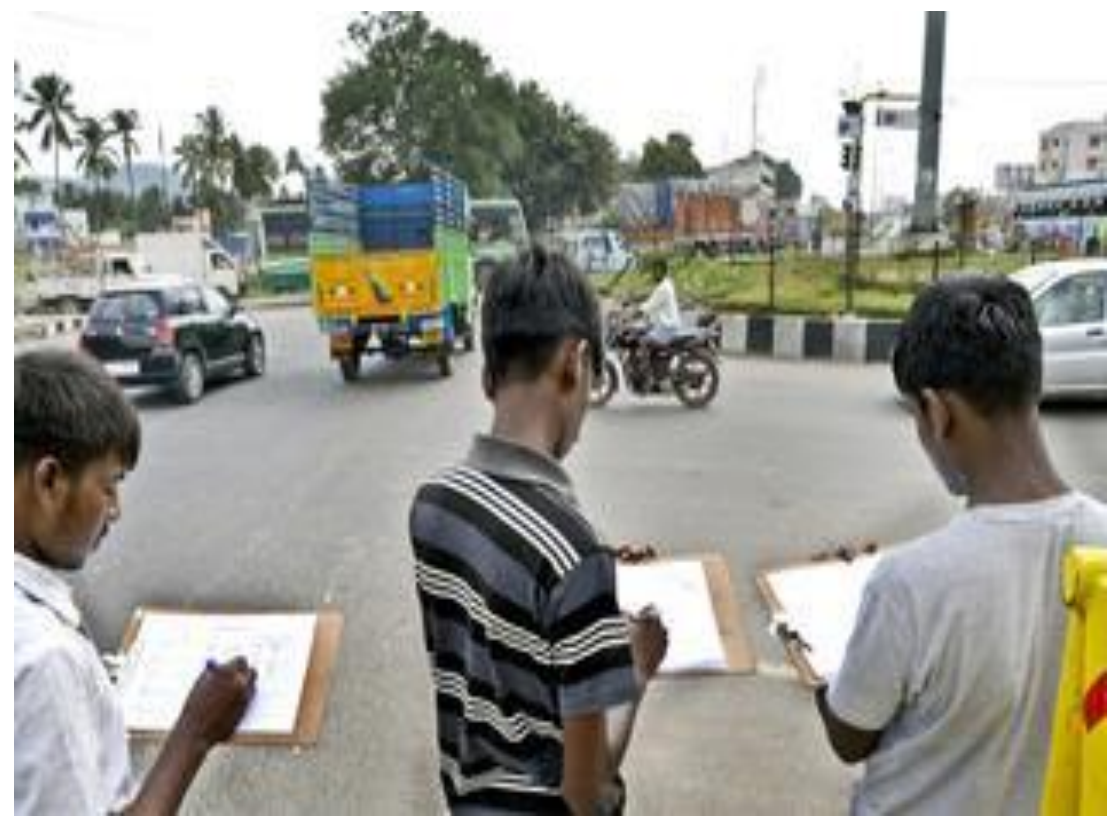

Figure-9Traffic Study for Hourly Average Vehicles Count

\subsection{Use of Emission factors}

An emission factor is a statistical average of the rate at which the air pollutant is exposed to the atmosphere as a result of various human activities such as combustion, divided by the rate of that activity [28]. Current practice of usage of emission factors in EPA- USA, California stove of USA, UK and India will be discussed and considered

\subsection{Estimation of concentration of pollution}

Different fuel usage such as kerosene, LPG, wood, Petrol, and Diesel in each ward have to be quantified and multiplied with appropriate emission factors prescribed by EPA-USA.

$\mathrm{E}=\mathrm{A} \times \mathrm{EF}$ Eq.(1)

where, $\mathrm{E}=$ emissions (amount of $\mathrm{SO}_{2}$ etc)

$\mathrm{A}=$ activity data (liters of fuel, $\mathrm{kg}$ of cement)

$\mathrm{EF}=$ emission factor $\left(\mathrm{kg} \mathrm{CO}_{2} / \mathrm{liter}\right.$ of fuel, $\mathrm{kgCO}_{2} / \mathrm{kg}$ cement $)$

"Activity Data" $(\mathrm{A})=$ Data on the magnitude of human activity resulting in emissions or removals taking place during a given period of time (liters of fuel consumed, etc)

"Emission Factor" $(\mathrm{EF})=$ coefficient that relates the activity data to the amount of chemical compound which is the source of later emissions 


\title{
3.4 Application of GIS Technique
}

Using the GIS software, the thematic maps could be prepared to show the following items:

- Concentration map of $\mathrm{CO}$ by point source

- Concentration map of $\mathrm{HC}$ by point source

- Concentration map of NOx by point source

- Concentration map of $\mathrm{SO}_{2}$ by point source

- Concentration map of CO by Area source

- Concentration map of HC by Area source

- Concentration map of NOx by Area source

- Concentration map of $\mathrm{SO}_{2}$ by Area source

- Concentration map of $\mathrm{CO}$ by line source

- Concentration map of HC by line source

- Concentration map of NOx by line source

- Concentration map of $\mathrm{SO}_{2}$ by line source

- Overall concentration of $\mathrm{CO}$ in the study area

- Overall concentration of $\mathrm{HC}, \mathrm{SO}_{2}$ and $\mathrm{NO}_{\mathrm{x}}$ in the study area

\section{BENEFITS OF THE PROPOSED STUDY}

i) The emission inventory will provide the most elemental basis for planning air pollution reduction strategies and evaluating their results.

ii) Emission inventory helps the government organizations for policy farming and decision making in any air pollution control programme.

iii) By implementing the air pollution control strategies based on emission inventory, the life of human beings and live stocks will be protected against harmful effects.

iv) for various "Policy-making purposes".

v) Characterization of Temporal Emission Trends.

vi) Tracking trends in emissions over time.

vii) To access the effectiveness of Air Pollution Policy.

viii) Development of Urban Strategies.

ix) Emissions Budgeting for Regulatory and Compliance purposes.

x) Prediction of Ambient Pollutant Concentration using Air dispersion models (as input to Air Quality models).

xi) As input to exposure and risk assessments.

xii) Non-living materials like marbles, bricks etc can be protected against corrosive action of air pollutants. Thus, the Civil engineering structures could be protected.

xiii) The various sources responsible for the emission of the major harmful gases will be identified clearly and the annual total emission concentration of the major air pollutants will be ascertained. The output of the proposed study could be more helpful for bringing a sustainable environment with clean air in Ambo town by introducing air pollution control strategies. In general, Emission inventory helps to bring the sustainable environment in a town.

\section{CONCLUSION}

The proposed study is the first attempt to observe the level of indoor and traffic pollution in a growing town, Ambo. Hence, very serious effort could be taken to identify the emission level with the help of educational institutions in the study area. With the help of the thematic maps, the municipality / corporation could implement very stringent effort to control the air pollution problems in Ambo town.

\author{
Appendices \\ IAP: Indoor Air Pollution \\ ARI: Acute Respiratory Infection \\ CO: Carbon Monoxide \\ HC: Hydro carbon \\ $\mathrm{SO}_{\mathrm{x}}$ : Sulphur oxides \\ $\mathrm{NO}_{2}$ : Nitrogen dioxide \\ CPCB: Central Pollution Control Board \\ EPA: Environmental Protection Agency \\ UK: United Kingdom \\ USA: United State of America \\ LPG: Liquefied Petroleum Gas \\ MSL: Mean Sea Level
}




\section{REFERENCES}

[1]. Rehfuess, E., Mehta, S. and Pru“ ss-Ustun, A. Assessing household solid fuel use: multiple implications for the millennium development goals. Environ. Health Perspect 2006;114:373-378.

[2]. Murray C, Lopez A. Global mortality, disability, and the contribution of risk factors: Global Burden of Disease Study. Lancet 1997a; 349: 1436-1442.

[3]. Murray, C.J.L. and Lopez, A.D. (1997b). Mortality by cause for eight regions of the world: Global Burden of Disease Study. Lancet 1997b; 349:1269-1276.

[4]. Smith KR. National burden of disease in India from indoor air pollution. PANAS 2000a;97 (24):13286-13293

[5]. Ezzati M, Alan Lopez D, Rodgers A, Hoorn SV, Murray CJ. Selected major risk factors and global and regional burden of disease. The LANCET 2002a; 360(9343):1347-1360.

[6]. Smith KR, Mehta S . The burden of disease from indoor air pollution in developing countries: comparison of estimates. International Journal of Hygiene and Environment 2003;206(4-5):279-289.

[7]. World Health organization (WHO). Indoor air pollution: National burden of disease estimates. WHO 2007.

[8]. Smith KR. Indoor air pollution in developing countries. The Lancet 1991; 337:359.

[9]. Smith KR, Samet JM, Romieu IBruce N. Indoor air pollution in developing countries and acute lower respiratory infections in children. Thorax 2000b; 55:518-532.

[10]. Ezzati M, Kammen D. Indoor air pollution from biomass combustion and acute respiratory infections in Kenya: an exposureresponse study. The Lancet 2001a; 358 (9282): 619-624.

[11]. Wafula EM, Onyango FE, Thairu H, Boleij JS, Hoek F, Ruigewaard P, Kagwanja S, DeKoning H, Pio A, Kimani E, et al. Indoor air pollution in a Kenyan village. East Afr Med J. 1990;67(1):24-32.

[12]. Terblanche AP, Nel CM, Opperman L, Nykes H. Exposure to air pollution from transitional household fuels in a South African Population. J Expo. Anal. Envronm.Epidemiol 1993; 1:15-22.

[13]. Ezzati, M. and Kammen, D. Evaluating the health benefits of transitions in household energy technologies in Kenya. Energy Policy 2002b; 30:815-826.

[14]. Tumwesigire SC, Barton T. Environmental risk factors for acute respiratory infections among children of military personnel in Uganda. East Afr. Med. J. 1995; 72:290-294.

[15]. Ellegard A. Cooking fuel smoke and respiratory symptoms among women in low-income areas in Maputo. Environ Health Perspect1996; 104(9):980-985.

[16]. Mishra V, Retherford RD. Cooking smoke increases the risk of acute respiratory infection in children. Fam Health Surv Bull. 1997;8:1-4.

[17]. Balakrishnan K, Parikh mJ, Sankar S, Padmavathi R, Srividya K, Venugopal V, Prasad S, Pandey VL. Daily Average Exposures to Respirable Particulate Matter from Combustion of Biomass Fuels in Rural Households of Southern India. Environ Health Perspect 2002; 110:1069-1075.

[18]. McCracken J, Charron D. Evaluation of the Efficacy and Effectiveness of the EcoStove for reducing indoor air pollution exposures among Nicaraguan women. Center for Entrepreneurship in International Health and Development. Energy Sector Management Assistance Program. World Bank 2003.

[19]. Balakrishnan, K Sankar S, Padmavathi R, Sumi M, Smith KR. Exposure assessment for respirable particulates associated with household fuel use in rural districts of Andhra Pradesh, India. Journal of Exposure Analysis and Environmental Epidemiology 2004; 14, S14-S25.

[20]. Dasgupta S, Huq M, Khaliquzzaman M, Pandey K, Wheeler D. Indoor air quality for poor families: new evidence from Bangladesh. Indoor Air 2006;16: 426-444.

[21]. Jin Y, Zhou Z, He G, Wei H, Liu F, Tang N, Ying B, Liu Y, Hu G, Wang H, Balakrishnan K, Watson K, Baris E, Ezzati M. Temporal distributions of multiple air pollutants in four Chinese provinces. Environ. Sci. Technol., 2005; 39 (24):9431-9439.

[22]. Ayazika W. Health related effects of traditional biomass fuels: the Ugandan case study.

[23]. World Health Organization. WHO Guidelines for Air Quality. WHO Publications, Geneva, Switzerland, 1999.

[24]. Central Statistical Authority (CSA) Ethiopia. Statistical Abstract 2007. Addis Ababa, Ethiopia.

[25]. Central Statistical Agency (CSA Ethiopia) and ORC Macro. Ethiopia Demographic and Health Survey 2005. Addis Ababa, Ethiopia and Calverton, Maryland, USA: Central Statistical Authority and ORC Macro 2006.

[26]. Abera Kumie, Air Pollution in Ethiopia: Indoor Air pollution in a rural Butajira and Traffic Air pollution in Addia Ababa 2009.

[27]. Thanappan Subash, Rapid Emission Inventory for Cuddalore Industrial Town of Tamilnadu, India- a case study. International Journal of Environmental Science and Technology, 1(2): 20-26, 2015. 